\title{
NIKE CORRE: Generation Y Moves the Running Market
}

\author{
Thiago Simão Marcondes Reis, Alessandra Morgado Ramiro de Lima and Angelo Maia Cister \\ Federal University of Rio de Janeiro, Rio de janeiro 22290 240, Brazil
}

\begin{abstract}
Focus on customer experience has proven to be one of the most important tools for the acceptance of the message of a brand by Millennials (Generation Y). The aim of this study is to demonstrate how Generation Y influences, through their behavior and customs, the decisions to be made by the marketing area of companies. In this sense, the study seeks to demonstrate this situation by addressing the running market, which is consistently growing in Brazil and has unexplored niches, as in the case of a group of young runners who belong to Generation Y that called the attention of Nike's running segment, and was the focus of this research study. The case study was conducted by the qualitative method, based on an empirical investigation, in addition to a literature review. In this sense, it addressed the emergence of Generation Y, and how was the progress of the media that monitored it during this transition, going through multi-platform advertising. This approach is followed by a study of the running market and the role of Nike in it, how the project emerged and its relationship with Generation Y's behavior.
\end{abstract}

Key words: Generation Y, running in Brazil, marketing strategy, consumer behavior studies, Nike Corre.

\section{Introduction}

Generation $Y$ has been a much discussed subject in the business sphere. Its influence in the face of the buying decisions within households and companies has been increasingly valued before their early relationship with technology and the internet [1]. For a better understanding of this generation, analyzing the history of generations and making a comparison of behaviors and characteristics of the generations, such as the media is necessary.

Born in the 1980s and 1990s, and also known as the "Millennials" Generation or Internet Generation, members of Generation $\mathrm{Y}$ are characterized by multitasking, for their lack of patience with long and time-consuming processes, since they are fond of diversity, immediacy, freedom and change [2].

These young people grew up, entered the labor market and are consequently obtaining greater financial autonomy and making their own buying decisions.

It turns out the way decision-making is made has changed compared to previous generations. Currently,

Corresponding author: Angelo Maia Cister, Ph.D., professor, research field: strategic studies and data mining. young people use personal or online social networks of influential groups they admire to determine what they will consume [1].

Loyalty to certain brands becomes more volatile due to the detachment of young people [2]. Bearing that in mind, brands like Apple, Nike and Coca-Cola, for instance, outline characteristic strategies for that generation.

The use of online media and new media opportunities becomes the main weapon of the companies to attract and dominate this category. Focus is no longer traditional advertising in newspapers and on television; today, focus is on the experience young people can have through activations of Viral Marketing, which is communication propagating without much effort among thousands or millions of people, resembling what a virus goes through [3].

The aim of this study is to demonstrate how Generation $\mathrm{Y}$ influences, through their behavior and customs, the decisions to be made by the marketing area of companies. Through this analysis, we can observe the progress of the media as generations pass and how communication with the current generation must behave. 
The study seeks to demonstrate this situation by addressing the running market, which is rapidly growing in Brazil and has unexplored niches, such as the group of young runners that belong to Generation Y, who caught the attention of Nike's running segment. In order to illustrate the influence of Generation $\mathrm{Y}$ in marketing strategies, the case of the \#Coisadaboa running group was studied; it was promoted by Nike focusing on young people aged between 18 and 25, along with an analysis of the running market in Brazil; also, the importance of the activation of this generation in this sport will be explained.

\section{Literature Review}

\subsection{The Progress of the Media Along with the Growth of a Generation}

Born between the early $80 \mathrm{~s}$ and the end of the $90 \mathrm{~s}$, Generation $Y$ youngsters grew amid a time of technological revolution, this generation was formed by being bombarded by the amount of information and the easy access they had to obtain it. Generation Y is also known as Digital Generation, Internet Generation [1] or Millennials [4].

This Digital Generation is considered a by-product of the 80s, since it followed the horror that narcissistic behavior caused, they seek the possibility of offering their children a lifestyle they did not have. There is an overall concern of not being home while working, and of seeing their children "abandoned" at home. Young people today show a greater concern in making the world a better place to live in. The movements for environmental conservation, for example, have never been as strong as they are for this generation [5].

At the same time, the Millennials shocked previous generations by their questionings at home and in companies. Wherever they are, the presence of Generation Y is actively noted, because these young people are always looking for new answers, for breaking paradigms, and are influenced by the internet and its vast content available to confront information.
These Generation Y youngsters, in turn, spend their time among cutting-edge technology devices, which were part of their family and social circle full time. Youngsters had access to a number and variety of information that no other generation did. The contact of this generation, due to the existence of other media and its inherent characteristic as to the ability to multitask and be multi-connected to several tools, simultaneously, generates a more superficial contact with traditional media, such as radio, newspapers and television. That fact changes consumption patterns and how companies should communicate with these young consumers.

What happens today is that young people are more involved, exposed and consequently more influenced by their friends, and the views expressed by them in social networks (such as Facebook, Twitter, Orkut, Myspace, among others), because they have stronger ties than that to recommendations of celebrities or of brands themselves [1]. It turns out this fact is opposite to what happened with previous generations. If then celebrities were the ones who influenced and dominated shopping decisions, today this fact is more balanced as the opinion of friends, through word of mouth, has been increasingly valued.

This generation is said, and no doubt, to be the most connected, a fact proven given that the physical barriers that prevented greater contact with other cultures were demolished by the great technological advances of this period. Social (virtual) networks became tools for carrying out social interactions, even the most complex ones.

While a representative of the Baby Boomer Generation apathetically watched television, on average about 22 hours a week, the young people of Generation Y watch less TV, or while they watch it, they simultaneously interact with other actions, such as surfing the internet, listening to music or talking on the phone [1]. The internet has become a chance to explore personality characteristics of Generation Y, such as to communicate, collaborate and create 
together without the need to leave the other existing media completely aside.

From the moment one realizes that Generation Y has its behavior completely changed by the environment it is in, through physical and social influences, one must understand that communicating with these young people should accompany this behavioral transition from the previous generation to this one. While radio and television were the main media for the older generations, the Digital Generation consumes the content propagated by these vehicles simultaneously with other activities, such as studying, chatting with friends or spending time surfing the Internet [10].

If beforehand there was a very important endorsement by celebrities and in customer communication through media, such as newspapers and television, from the time there was a change in the behavior of young people today, companies had to readjust accordingly. It is noticeable that young people are increasingly connected to social networks.

Importantly, the internet can exercise the link between communication, collaboration and the creation of products, services, and trends among people with different influences and physically distant locations, however, in this borderless world, this feature ceases to influence the ability of doing things by society itself.

The increase in access to social networks like Facebook, Twitter, Instagram, among others, should be the new basis for the internet. By having the characteristic of exposing their tastes, thoughts and opinions, Generation Y puts aside their privacy, and ultimately facilitates not only communication among young people, but also communication between companies and young people.

Based on the study of the Maslow pyramid of needs, where it is stated that after the basic needs of survival and security, the most important factor is acceptance in the social environment, which becomes one of the most likely ways to explain our receptivity and exposure in the emergence of social media [5].

If currently there is great ease in communication among young people, this is due to the advancement of technology and the popularity of channels, such as social media. In these media, led by young people who use their resources to quickly exchange information, there are plenty of options that play the communication channel's role, restricting subjects by interests or other divisions.

In addition to the internet breaking barriers of distance and other limitations, it starts to empower the voices of friends as influencers in the buying process, demonstrating the capacity of its decentralized power of information, which makes adjustments between the production chain and the consumption chain necessary. Since, through this capacity, discernment to measure the correct value of a certain product or service is greater [1]. The key point in question for companies is finding ways to win the opinion-makers, and that, as will be seen later, applies perfectly in the case studied.

Among the people who disseminate opinions and trendsetting, three groups can be created to differentiate them. They are: connectors, pundits and sellers [6], and as much as this concept has been discussed in the book "The Tipping Point" at a time when online social networks were not so popular.It is possible to identify this division today. Connectors are the greatest broadcasters of marketing messages, they are usually the first users lured by companies. Characterized by a wide social circle, they have the ability to pass the message in a wide range. Pundits can be understood as authorities in certain subjects through reputations won by what is presented by them in their own virtual environment. Their advantage is the non-restriction of their influence in their social circle, since they are considered experts in a given subject and their opinion is reproduced on multiple channels, and it can even reach "strangers". Sellers, in turn, influence through their ability to generate a buzz. They use their inherent personality characteristics, such as charisma and great negotiating power, but act 
in order to take profit from what they sell.

The problem is information overload, which reduces the diffusion capacity and influence of the message. This is due to the custom of that generation in reporting product and service satisfaction in virtual means. In order for companies to more objectively enter networks of influence, they must explore niche markets, rooting the message that the company intends to communicate. This fact makes the relationship between brand and consumer, more solid [1].

\subsection{The Importance of Online Content for Companies}

Companies should recognize the need for a solid strategy in social media. There needs to be an integration with what they do, and their presence in the digital media is only one more part of their business. This requires time, commitment and quality content that interacts between online and offline means.

For better interaction with young people through digital media, it should be understood that the most important factor for a better engagement of this generation with the brand is the content that will be made by the company. Its importance is such that it changes the perception of the brand in a way advertising is not able to.

If the company is willing to have a voice in social media, it will be heard by the message it passes, if the content is deemed relevant to Millennials, that voice becomes amplified and its reach significantly improved, allowing it to reach more people through word of mouth promoted by the very customers of the brand that replicate the message. The informality of social networks like Facebook and Twitter, allows the message of the brand to be more freely transmitted by taking advantage of the presence of consumers in the media for them to integrate the message.

Everything is based on building a company-consumer relationship. The quality of such built relationship, and the confidence given by the company can mean a lot in this network. One should keep in mind the need to genuinely pass the information on. The internet being an open space should be treated transparently. In it, the integrity of the message passed by the company can consolidate campaigns or majorly ruin its image.

If consumers of the Internet Generation consider the message to be valid, it is replicated from niche communities and will spread through those who play an influential role in the network, viralizing 1 the message. Among the factors that contribute to the viralization of a message, we can mention the excellence of content and its uniqueness, the aesthetics presented by it, the ability to engage, its expressive and functional value, the ability to evoke feelings and sensations in the consumer, the embodiment of communication and its cost.

The effectiveness of a campaign can be significantly increased if the advertiser knows to take advantage of gaps in entering the influential networks of its consumer. The recommendation of friends and viralization of campaigns make it more acceptable to young people, because they assume what their friends recommend is worth considering. Due to that, the mission of companies is finding the ideal medium to reach key consumption influencers in small social cycles for them to share and pass on the message initially propagated by the brand only.

For more effective advertising in social media, one should pay attention to what consumers express, such as customs, decisions and issues, which they are more engaged in. Before talking, it is necessary to listen to what the customer says, what they want, and then decide on the best way to get to them.

The power of multi-directional advertising, i.e., divided into several platforms, is such that communications made in the more traditional media seek to integrate digital media into the campaign for having an improved conversation with the consumer.

\footnotetext{
${ }^{1}$ Neologism that means to spread in order to create an effect similar to that of a virus.
} 


\section{Methodology}

This study, regarding its purposes, was exploratory. As for the means, research was bibliographical and field. For this field of research, the universe considered was that of athletes who have participated at least once in the \#Coisadaboa program and are part of the group aimed at discussing the program in question on Facebook. Underprivileged samples in the study refer, therefore, to runners who were once part of the program and were not able to view the message, since they did not attend the group in question.

The sample was defined by accessibility, i.e., selecting elements due to the ease of access to them [7]. However, although the main definition is accessibility, in the background, we used a stratified method, not proportionate in terms of gender to make sure runners of both genders were contemplated. As the number of samples, 100 responses were collected to absorb a reasonable mix of project participants and to filter in order to only analyze the result of Generation Y.

The study can be defined as qualiquanti since, for understanding the behavior of program participants, it is necessary to work with a complex, subjective and dynamic phenomenon involving social groups in generating information. With regard to the nature of the research, it can be characterized as applied, since the purpose of the study has a specific application, which is to deepen the knowledge on the phenomenon of changes in the Generation Y consumer's behavior after the emergence of the project developed by Nike Corre. In order to achieve the objective of this case study, data collection and information relevant to the investigation and understanding of the issue proposed was carried out by using the survey method.

The research was developed from issues deemed relevant in the means of sport, and they could differ in perceptions regarding the project. The questionnaire was sent through a link in a Facebook group that gathers project participants. The total achieved sample was 100 people, and a filter was placed in the first issues in order for us to work on Generation Y only.

After collecting data, content analysis was made, which involved the interpretation of the interviews supported in the cited information materials. It should be noted that the search for understanding of sporting goods consumer behavior suffers a bit of influence, as such consumers are already in the midst of a community organized by Nike.

\section{Research Results}

\subsection{The Running Market in Brazil}

Considered one of the major sports in the world, Road Running has gotten to the mind, especially the feet of its practitioners. Since it is a simple sport without major limitations and adaptable to any location and weather, this sport is one of the most sought after by those who seek a healthier life. It is precisely from that ideal of a healthy life that one can explain increased participation, especially of young people over the years.

As mentioned before, there is a major concern of young people regarding aspects such as health and sociability, and running perfectly fills that gap. The sport itself is extremely simple and can adapt to the needs of each individual. In this quest for health, running is considered a step after walking, and due to the variety of distances and aspects that the sport involves, road running plays an increasing role in the lives of those who start running.

For young people who are eager to being rewarded, running gives them the pleasure of overcoming distances, or running the same distances in less time. Only in a few sports is the improvement of performance seen so clearly. In addition, the individuality of the sport in question becomes a positive point for young people, since it eliminates depending on someone else to practice it.

At the same time, the numerous opportunities of competing with friends and strangers through road running events that take over the offline world, or the world of applications and social networks, specific for 
this use, attract such a competitive and connected generation to this sport.

These characteristics put side by side, come to be decoys for Generation Y, because there is a great facility to adapt to the routines of those young people who increasingly spend more time with various chores.

According to research from the Datafolha Institute, in Brazil, $75 \%$ of young people who practice sports are aged between 18 and 24, and this same survey also reveals that $38 \%$ of the young people who were interviewed walk or practice some running modality, which added together that would be the 4th most practiced sport by young people, second only to soccer, volleyball and swimming [8].

The running industry is mainly composed of the organizers of sporting events, companies that produce and sell sporting goods or those used during physical activities, and sports advisory services, travel agencies related to sports and the specialized media.

Following the growth rate of the sport worldwide, Brazil, since it is considered a small market, especially compared to the US market, calls attention due to the high growth in number of participants and number of competitions.

It is estimated that today, the number of road runners who participate in about 730 events in the country, is something around three to four million people, derisory figure compared to the United States, which according to the Sports Goods Manufacturers Association (SGMA), this figure reaches twenty-five million people.

Regarding the number of practitioners, Joao Traven, of company Spiridon, responsible for organizing events such as the Rio de Janeiro Marathon, says since such activity is considered healthy, cheap and democratic, it became trendy, and upon the existence of several race groups, their behavior became "tribal", since they practice activities together, establishing a friendly relationship through running.

It is noticeable that Brazilians are gradually becoming fond of running, mainly young people and residents of capital cities, places where most competitions occur. This result is so visible, that Rede Globo, the largest broadcast television station in Brazil, and one of the most accessed internet news portals, divided their broadcast programming and content area into fixed spaces for the sport to be addressed, called "Eu Atleta".

Therefore, the message running passes on regarding health and well being, which was restricted to large cities, will now be addressed at national level by one of the country's largest media outlets, through inserts in morning shows and an exclusive area regarding this subject in its portal. Many figures can illustrate this growth [9]. In the Southeast, for example, we can see such progress on the Table 1.

We can observe in the above table that besides the growth in the average of competitors per race, the representativeness of the region is falling, clearly demonstrating the increase in other regions of the country.

Another indicator that shows the increase in the road running practice in Brazil, is the sales of sporting shoes. In 2012, the segment grew 35\%, while the entire sporting shoes market increased 3\%. According to research conducted by GFK [9], the growth in road running in 2012 compared to 2011, caused the sport to overcome soccer regarding market share, as shown in the Table 2.

Table 1 Running in Southeast.

\begin{tabular}{llll}
\hline & 2007 & 2008 & 2009 \\
\hline Average of runners/competition & 3850 & 4115 & 4263 \\
Average of events (over 500 athletes) & 203 & 230 & 263 \\
National representativeness & $74 \%$ & $73 \%$ & $71 \%$ \\
\hline
\end{tabular}

(Source: SportTarget). 
Table 2 Running Market Share-GFK.

\begin{tabular}{llllll}
\hline Year & Running & Soccer & Leisure & Foreign & Domestic \\
\hline 2011 & $13 \%$ & $13 \%$ & $74 \%$ & $54.5 \%$ & $45.5 \%$ \\
2012 & $17 \%$ & $13 \%$ & $70 \%$ & $53 \%$ & $47 \%$ \\
\hline
\end{tabular}

(Source: SportTarget-2013).

It is estimated that in 2010 here in the country, the running competition market turnover was approximately BRL 3 billion, and between 2005 and 2010, the average business growth regarding the sport was $30 \%$ [11].

With this increasing running competition offer, there is also an increase in the number of companies, even from different sectors, that currently wish to associate their brand to the sport. Upon the perception of running as a healthy habit for athletes and upon the chance of reaching their consumers through experience, the result of that is that currently we can see the existence of competitions directly related to brands, such as Light Rio Circuit, Pão de Açúcar Relay, Fila Night Run, among many others or by sponsorship (advertising through smaller quotas) in the events. An example is the case of Rio Marathon organized by company Dream Factory, where from 2008 to 2011, the number of sponsors went from four to twelve, in addition to the quota value adjustment, the income of which went from BRL 1.5 million to BRL 6.2 million, only with these sponsors [11].

This form of advertising where companies associate their brand with a healthy practice and focus on the consumer experience results in an improvement of analytical rates, such as Share of Mind, which can be understood as the acknowledgement consumers have of a particular brand, and that mostly influences the consumer's buying decision.

That occurs, because when the customer is reached by advertising, in the form of experience, communication becomes indirect and, since it is not as noticeable as the more traditional ways of media broadcasting, it enables greater maximization of return added to communication during an event having a diversity of audience profile, and through diluted cost by sharing the space with other brands.

The road running domestic market reveals that although brands such as Adidas, Nike and Olympikus improved their participation in the sporting shoes market, evidenced by what can be observed during competitions, the presence of brands like Mizuno and Asics, which has always had a greater tradition towards running products, continue to lead the segment.

Another fact about running in Brazil and that stands out in the Crowe Horwath RCS research is that only $3 \%$ of runners are aged under 24. If this age group corresponds to a more communicative and influential generation among those who live together today, then the companies in this sector should take opportunities to explore the space left by the generation.

As noted earlier, it is precisely young people who communicate and evidence trends and strengthen the communication of the company through a virtual good content, what else do major brands need to work on that?

Today Nike needs almost nothing. But, it hasn't always been that way. First, let's go back into the brand's history a bit to better understand their strategy today.

\subsection{Nike and Generation Y: \#Coisadaboa Project}

There is no doubt Nike is one of the most reputable companies in the sports market. It has great presence in various sports, and it is well respected in all of them. Guided on endorsement by celebrities, the brand gained importance and prominence in various sports such as Soccer and players like Ronaldo Nazário, Basketball and the image of Michael Jordan, Golf and great champion Tiger Woods, tennis and Roger Federer, and that hardly happened to running. 
The curious thing is that the brand began precisely because of running, in 1971, with runner Phil Knight and coach Bill Bowerman, when they began to make their own running shoes. Much time has passed until Nike made other model of shoes successful in the market.

Then, in 2001 the company made a mistake that compromised the company's history in running for long. On that year there was the launch of tennis shoes with a shock absorption system composed of spring-shaped columns in the soles. Nike Shox had immediate and great acceptance of consumers to a point having shoes with four, eight or twelve springs was considered social status. The problem was, negative reports were received after some time of its use, since such shoes were associated to running.

This repercussion ended up giving a bad impression to the brand in the running segment, and Nike ended up leaving this market aside for a bit, which was an extremely wrong choice, because running started becoming very popular in that period.

After some time not focusing on this sport, Nike clearly started to invest in research and development of new running shoe models. New technologies and footwear models emerged and the company made its way back into the history of such sport, with the Nike Free shoes, which had the Lunarlon shock absorption technology, and more recently the Flyknit, shoes that eliminated material waste in $80 \%$ and became one of the lightest shoes on the market, due to its technology.

With the development of many products and technologies that help the sport, it was evident that Nike wants to resume the course of its origin and get more attention in the running market. Thus, there is nothing more understandable than exploring a market niche that influences predecessor and successor generations, and also has great acceptance regarding the brand, due to its extensive market presence.

Nike defended the view that consumers want to be part of the community, whether digital, virtual or physical. What customers want is to feel involved in the process. They really want to be engaged in it. That is one of the 11 precepts of the brand, which is the consumer who decides.

If the goal was to reach these young people, the entire company's strategy should be based on the customs and behaviors of their Millennial consumers. For that matter, the brand realized the need to reach consumers who adopt the message of the company, and propagate the communication in order to enhance the brand message through the influence scale.

Bearing that in mind, project \#Coisadaboa was created in Brazil in July 2011, such action was solely related to running, and mainly aimed at young people aged between 18 and 25. With two groups, one in Rio de Janeiro and one in Sao Paulo, the project started selecting young people who had some relationship with the sport, and had some relevance in their social circle, to serve as what Nike called "Ambassadors", and that the power of influence and of a message distributor was used in the best way in order to attract more people into this action.

It began providing sports material to the "Ambassadors", which drew attention in their social cycles. After all, who wouldn't want to practice sports with the support of one of the biggest sports brands? Regarding communication aimed at customer loyalty in such sport, the theme explored by the company was that running is addictive and that is the only beneficial addiction for one's body.

The message was explicitly directed to Generation $\mathrm{Y}$ from the moment it used a high impact campaign and associated the sport to health and wellness issues. For that, Nike used offline campaigns, which were also supported by online media by using various graphic elements and in different formats.

If in order to reach Generation $\mathrm{Y}$ a company should go after their consumers, that is exactly what Nike set out to do. Stickers posted in places like nightclub bathrooms and communication pieces conveyed in magazines aimed at young audiences, such as Rolling Stone, TPM and Trip, and advertisements in digital 
media, such as Facebook and Youtube, as seen below.

If the message was ready, the only thing left to do was the project to begin, so the brand would generate the content and look for it to be distributed somehow. If Generation $Y$ has such a great concern regarding aesthetics as to their looks, with the "need" of exposing their customs and life in the digital media, individualizing the content produced would have a greater effect, since, without making it evident, young people who practiced running would appear in photos of a photographer hired to cover the weekly workouts of the brand, and sharing such content in their social circle became an integral part of the indirect advertising of the brand.

The successful activation was so great that today, the brand's running page on Facebook (https://www.facebook.com/nikecorrebrasil), has about 2.0 million followers, and became the largest in the running segment, worldwide, and shortly after 1 year of the beginning of the project, the brand had achieved a significant figure of one million fans on Facebook. To further enhance this engagement by the community of runners, Nike bet on its social network focused exclusively on running, called Nike + .

Nike + can be defined as a centralized network of products and services for Nike consumers. The runner's activity can be monitored by using a Sports Kit or a cell phone application. As they run, the kit or the application provides relevant information to the runner, such as time, distance, pace, calories burned and even the distance ran so far.

After the activity is recorded, a result is consolidated in order to be analyzed and shared through a social network for runners, with the same service name, and passed on to other virtual communities, like Facebook and Twitter. Thus, enabling comparisons with friends and recording training and running progress.

Nike + social network is based on the principle of consumer experience, involving the social circles of its customers and allowing the analysis of the individual alone, able to receive feedback on their workouts, and incentive to competition in certain groups.

\section{Analysis and Discussion}

This research sought to verify the influence of Generation $\mathrm{Y}$ in marketing strategies through a study of the \#Coisadaboa running group, sponsored by Nike with a focus on young people aged between 18 to 25 . Of the 100 participants in the research, 59\% male and $41 \%$ female, only $65 \%$ were within the desired niche, runners aged between 18 and 30. So 65 people are listed as members of Generation Y.

Another result that we can see is that over $50 \%$ of the young people who were interviewed began to run after the start of \#Coisadaboa program and Health remains the main concern of young people and a key factor for them to practice sports, and $10 \%$ said they started running because they were encouraged by a friend.

Regarding the brand, the result of Nike Corre's work through \#Coisadaboa program is noticeable, where $68 \%$ of young people answered that the brand is mostly associated with running. Also in relation to the brand, 54\% said they did not use running shoes before the program. However, $85 \%$ bought a product after participating in the running group.

The result also highlights the importance of network influence through friends and the presence of the brand with content in digital media, where $63 \%$ of people said they learned about the program through acquaintances and $31 \%$ state to having seen it on social networks like Facebook and Twitter .The presence of the brand in these media is positively assessed, where $80 \%$ consider their interaction with the brand to be excellent or good.

Some results demonstrate the previously mentioned features of this generation. Such as, 57\% declared being a non-loyal consumer to the brand, and 63\% revealed they prioritize sustainable products, proving their concern over the environmental situation. 
Overall, \#Coisadaboa program is positively assessed (excellent or good) by $86 \%$ of research participants, which highlighted among the positive points of the project, factors such as sociability, organization, welcoming all classes without distinction, encouraging the practice of sport and a healthier life. Some participants recognized that the program works in a way to generate content, such as photos they post on Facebook, to win customers and promote the brand in order to increase sales. Still, it was considered to be positive.

However, some negative points also draw attention, even if they did not hinder project assessment. Issues such as lack of technical support, small social circles that are formed and prevent greater integration among the participants, lack of support for those aged over 25 and lack of diversification of the location were mentioned.

\section{Conclusion}

The key communication issue is to seek and engage the consumer in relation to the message passed by the company. For that, one should seek to encourage it primarily through customization, innovation and collaboration capabilities by exploring the customer's relationship with their networks of influence.

Thus, in order to have a positive return of word of mouth among its customers and potential consumers, especially Generation Y consumers, which were the focus of this study, companies should seek to exercise proper care in digital networks and also focus on consumer experience outside digital networks, making the use of multi-platform marketing. If this generation wants to be part of the process, it is necessary for links to be established to assure its presence, and that relationship should be noticeable by it and carefully worked on by the company.

Focus on customer experience has proven to be one of the most important tools for the message of a brand to be accepted by Millennials. The way it is established makes the advertising itself to take place subjectively and to avoid the rejection of the message, such as when the content generated by the brand is exposed only through more traditional media.

In addition, the company must always seek to format the content of its messages to situations that attract young people of Generation Y. For that matter, the company must thoroughly observe the behavior of these young people. If the generation is immersed in a digital medium, the company should take advantage of their ability to replicate messages more quickly than at other times, and the content should be produced in order to optimize this factor. The company should not place itself against young people, but walk side by side with them by tracking their movements, exploring their social cycles, and enjoying their characteristics, such as social responsibility, their concern with health and wellness and eagerness for new technologies, in order to base the development of its products and services.

From the moment we found that the individualization of consumer behavior makes the market niches smaller, and they exist in larger quantities, the company should explore a deeper degree of relationship and be more attentive to several existing opportunities.

According to the results obtained in this study, one can conclude that work involving generation $\mathrm{Y}$ through strategies engaging consumer experience reveals to be a correct strategy. This is proven by the existing association of the public studied to the running market and the brand in question, as evidenced in the outcome of the research.

It is evident that the influence of Generation $\mathrm{Y}$ in marketing strategies is easily noticed through the process of companies in observing their customs and trends, tailoring their message according to what young people think without it sounding fake, communicating through the means of communication used by them, exploring the individuality of the generation and their ability to replicate messages more objectively and quickly, aiming to engage these young consumers. For that matter, one of the most efficient ways is working 
on consumer experience.

This experience, if well managed, made with quality and explored along with good communication through channels of communication with young people, results in the improve perception and, hence, a stimulus for buying the brand's products or services.

\section{References}

[1] Tapscott, D. 2010. A hora da geração digital: Como os jovens que cresceram usando a internet estão mudando tudo, das empresas aos governos. Rio de Janeiro: Agir Negócios. (in Portuguese)

[2] Oliveira, S. 2010. Geração Y: O Nascimento de uma nova versão de líderes. São Paulo: Integrare Editora. (in Portuguese)

[3] Torres, C. 2009. A Bíblia do Marketing Digital. Novatec. (in Portuguese)

[4] Lancaster, L. C., and Stillman, D. 2011. O Y da questão: Como a geração $Y$ está transformando o mercado de trabalho. São Paulo: Saraiva. (in Portuguese)

[5] Qualman, E. 2010. Socialnomics: How Social Media
Transforms the Way We Live and Do Business. Wiley. (in Portuguese)

[6] Gladwell, M. 2001. The Tipping Point. New York: Back Bay Books.

[7] Vergara, S. C. 1998. Projetos e relatórios de pesquisa em administração. São Paulo: Atlas, 1998. (in Portuguese)

[8] Ponto, E. 2012. A realidade esportiva que o jovem brasileiro quer para si. Accessed February, 20, 2013. http://pontoeletronico.me/2012/11/08/a-realidade-esportiv a-que-o-jovem-brasileiro-quer-para-si/. (in Portuguese)

[9] Sporttarget. 2013. O Running no Brasil. Uma breve síntese de mercado. Accessed March, 03, 2013. http://www.slideshare.net/SPORTTARGET/sport-targeto-running-no-brasil-uma-breve-sntese-de-mercado. (in Portuguese)

[10] Ibope Mídia. 2012. Gerações Y e Z: Juventude Digital. Accessed February, 26, 2013. http://www4.ibope.com.br/download/geracoes\%20_y_e_ Z_divulgacao.pdf (in Portuguese)

[11] Isto É Dinheiro. 2011. A corrida das marcas. Accessed February 20, 2013.

http://www.istoedinheiro.com.br/noticias/6048_A+CORR IDA+DAS+MARCAS. (in Portuguese) 